\title{
Effective Power Sharing Approach for Islanded Microgrids
}

\author{
M. I. Azim and M. A. Hossain \\ School of Engineering and \\ Information Technology \\ The University of New South Wales \\ Canberra, ACT 2610, Australia \\ m.azim@student.unsw.edu.au, \\ md.hossain6@student.adfa.edu.au
}

\author{
M. J. Hossain \\ Griffith School of Engineering \\ Griffith University, Gold Coast \\ QLD 4222, Australia \\ j.hossain@griffith.edu.au
}

\author{
H. R. Pota \\ School of Engineering and \\ Information Technology \\ The University of New South Wales \\ Canberra, ACT 2610, Australia \\ h.pota@adfa.edu.au
}

\begin{abstract}
A droop control-based approach of effective power sharing among four parallel inverter-interfaced generators in an islanded microgrid has been proposed in this paper. Droop control strategy is applied during load change in islanded microgrid system in a way that power sharing among all the generators is also equal. This paper describes the small-signal stability analysis method to select the control gains needed to stabilize the considered microgrid system with desired power sharing among different generators connected in various buses. The real powers of distributed-generation (DG) units are shared based on the frequency, whereas a linear model is used to tune controller for reactive power sharing in this paper. The proposed power sharing scheme is verified with the help of MATLAB simulation.
\end{abstract}

Index Terms-DG units, voltage-source converters (VSC), microgrid, droop control, power sharing.

\section{INTRODUCTION}

Presently microgrids are getting popularity throughout the world as they are small-scale, self-contained, medium/low voltage electric power system (EPS) [1]. They can be termed as an interconnection between DG units and loads [2], which ensures higher utilization of renewable energy, reduction of transmission losses, low capital investments and reliability of electricity supply [3], [4]. Frequent load change is noticeable in microgrids [5] and they do not have the rotating inertia for power balance [6]. Co-existence of multiple DG units may affect their sound operation [7]. Therefore, it is necessary to implement control schemes in microgrids.

Both centralized and decentralized control methods are reported in [8]-[10] in order to maintain proper balance between demand and power generation, along with suitable system voltage and frequency regulation. Decentralized controllers are preferred owing to the fact that they can operate without communication. They are practical and reliable [11]. Droop control is one of the most common approaches which emulates the droop characteristic of synchronous machines [12], [13]; in which frequency plays a vital role in real power sharing. On the other hand, reactive power depends on voltage [14][16]. In existing literature there is no sufficient information regarding equal load sharing among DG units if they are of same ratings. This is important because unequal load sharing may result in unwanted temperature increase in one DG unit [17]. As a consequence, the efficiency of that DG unit may decrease.

This paper presents an approach; in which equal power sharing is highlighted among various DG units. This is done by selecting proper droop gains, along with using same type of transmission lines in all the buses, i.e, line impedances are equal. In this paper, real power is shared according to the rateof-change of inverter voltage angle (frequency). This paper also describes a linear model based reactive power sharing as it can not be shared in microgrids based on the terminal voltage.

The remainder of the paper is structured as follows: in section II, islanded microgrid system is modeled. Section III provides system stability analysis with droop control scheme. Effective real-reactive power sharing approaches are modeled in Section IV and Section V respectively. Section VI deals with the simulation results and conclusions are outlined in the final section.

\section{Modeling OF Microgrid System IN ISLANDED MODE}

Islanded microgrids can be represented by inverterinterfaced DG units and loads. Voltage sources, with magnitude and phase, can be used to represent DG units connected to the system via inverters. In Fig. 1, buses 1-4 are DG buses and bus- 5 is a load bus.

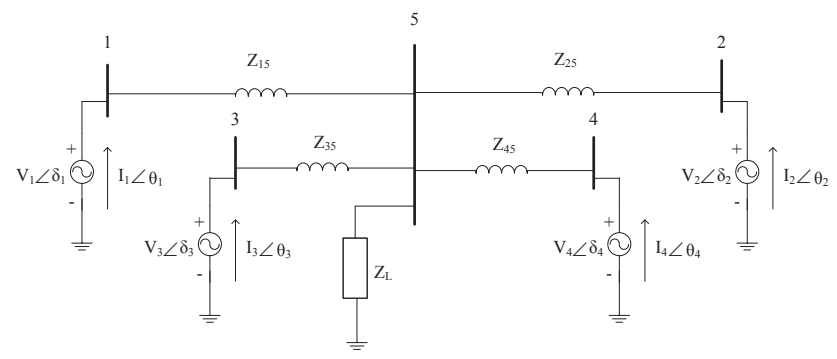

Fig. 1: Single-line Diagram of a Simple Islanded Microgrid 


\section{System Stability Analysis With Droop CONTROL SCHEME}

Decentralized droop control algorithms for DG units to share load in microgrids are studied in [18]-[22]. According to these algorithms, the rate-of-change of phase angle decreases if the measured active power is greater than the reference value, whereas when the measured reactive power becomes larger, voltage is reduced. The droop equations can be written as $(i=1,2,3,4)$ :

$$
\begin{aligned}
\Delta \dot{\delta}_{i} & =-k_{p_{i}}\left(P_{m_{i}}-P_{i}^{0}\right) \\
\Delta V_{i} & =-k_{q_{i}}\left(Q_{m_{i}}-Q_{i}^{0}\right)
\end{aligned}
$$

where, subscript $m$ stands for measured values.

The gains of the proposed droop controller are chosen arbitrarily according to the eigenvalue analysis of the linearized closed-loop system. In this paper, $k_{p_{1}}=6, k_{p_{2}}=6, k_{p_{3}}=6$, $k_{p_{4}}=6, k_{q_{1}}=0.06, k_{q_{2}}=0.06, k_{q_{3}}=0.06$ and $k_{q_{4}}=0.06$.

Let the real and reactive power measurement sensors have a first-order dynamics and their transfer functions [19] $(i=1,2,3,4)$ :

$$
\frac{P_{m_{i}}(s)}{P_{i}(s)}=\frac{w_{\mathrm{f}}}{s+w_{\mathrm{f}}} ; \frac{Q_{m_{i}}(s)}{Q_{i}(s)}=\frac{w_{\mathrm{f}}}{s+w_{\mathrm{f}}}
$$

where, $w_{\mathrm{f}}=12 \mathrm{rad} \mathrm{s}^{-1}$

Islanded microgrid model is linearized in this paper to understand the dynamics of the microgrids. The admittance matrix of 5-bus microgrid can be expressed as:

$$
Y_{\mathrm{b} u s}=\left[\begin{array}{ccccc}
\frac{1}{Z_{15}} & 0 & 0 & 0 & -\frac{1}{Z_{15}} \\
0 & \frac{1}{Z_{25}} & 0 & 0 & -\frac{1}{Z_{25}} \\
0 & 0 & \frac{1}{Z_{35}} & 0 & -\frac{1}{Z_{35}} \\
0 & 0 & 0 \frac{1}{Z_{45}} & 0 & -\frac{1}{Z_{35}} \\
\frac{1}{Z_{45}} & 0 & -\frac{1}{Z_{45}} & & \\
-\frac{1}{Z_{15}} & -\frac{1}{Z_{25}} & -\frac{1}{Z_{35}} & -\frac{1}{Z_{45}} & Z_{f}
\end{array}\right]
$$

where, $Z_{f}=\frac{1}{Z_{15}}+\frac{1}{Z_{25}}+\frac{1}{Z_{35}}+\frac{1}{Z_{45}}+\frac{1}{Z_{L}}$, $Z_{15}=Z_{25}=Z_{35}=Z_{45}=j 0.15 \mathrm{pu}, Z_{L}=1 \mathrm{pu}$

For simplicity of linear analysis, $Y_{\mathrm{b} u s}$ matrix is reduced by combining voltage-source buses in group ' $1-3$ ' and load bus in group ' 4 ' and the microgrid becomes a 4-bus system. $(i, j=1,2,3,4 ; j \neq i)$

$$
Y_{\text {reduced }_{i j}}=Y_{i j}-Y_{i 4} Y_{44}^{-1} Y_{4 j}=G_{i j}+j B_{i j}
$$

The power flow of 4-bus microgrid system can be written as [20]:

$$
\begin{aligned}
P_{i} & =\sum_{j=1}^{3} V_{i} V_{j}\left(G_{i j} \cos \delta_{i j}+B_{i j} \sin \delta_{i j}\right) \\
Q_{i} & =\sum_{j=1}^{3} V_{i} V_{j}\left(G_{i j} \sin \delta_{i j}-B_{i j} \cos \delta_{i j}\right)
\end{aligned}
$$

Let define $\Delta P_{m_{i}}=P_{m_{i}}-P_{i}^{0}$ and $\Delta Q_{m_{i}}=Q_{m_{i}}-Q_{i}^{0}$. The system described by (1) and (3) can now be linearly represented as $(i=1,2,3,4)$ :

$$
\begin{aligned}
\Delta \dot{\delta}_{i} & =-k_{p_{i}} \Delta P_{m_{i}} \\
\Delta \dot{P}_{m_{i}} & =-w_{\mathrm{f}}\left(\Delta P_{m_{i}}-\Delta P_{i}\right) \\
\Delta \dot{Q}_{m_{i}} & =-w_{\mathrm{f}}\left(\Delta Q_{m_{i}}-\Delta Q_{i}\right)
\end{aligned}
$$

where,

$$
\begin{aligned}
\Delta P_{i} & =\Delta P_{i \delta_{j}}^{0} \Delta \delta_{j}+\Delta P_{i V_{j}}^{0} \Delta V_{j} \\
\Delta Q_{i} & =\Delta Q_{i \delta_{j}}^{0} \Delta \delta_{j}+\Delta Q_{i V_{j}}^{0} \Delta V_{j}
\end{aligned}
$$

where, $i, j=1,2,3,4$.

The constants $\Delta P_{i \delta_{j}}^{0}, \Delta P_{i V_{j}}^{0}, \Delta Q_{i \delta_{j}}^{0}$ and $\Delta Q_{i V_{j}}^{0}$ can be obtained from (6) and (7). They represent the linearization of the system dynamics, which can be modeled with the above differential equations. For the system that is linearized at the equilibrium point after the load is changed to $\mathrm{j} \mathrm{pu}$, the eigenvalues are : $-12,-12,-12,-12,-6+j 24.2392,-6-j 24.2392$, $-10.952,-1.048,0,0,-12,-12$. It has been found from Figs. 2-6 that the eigenvalue analysis captures the system behavior.

\section{EFFective ReAl Power Sharing}

The system falls into steady-state if the changing rates of $\delta_{i}$ are the same, i.e.,

$$
\Delta \dot{\delta}_{1}=\Delta \dot{\delta}_{2}=\Delta \dot{\delta}_{3}=\Delta \dot{\delta}_{4}
$$

In this section, the equal power sharing characteristic of the controller is verified. In steady-state, $P_{m_{i}}=P_{i}$. From (8) and (13), it can be written,

$$
\Delta P_{1}=\frac{k_{p_{2}}}{k_{p_{1}}} \Delta P_{2}=\frac{k_{p_{3}}}{k_{p_{1}}} \Delta P_{3}=\frac{k_{p_{4}}}{k_{p_{1}}} \Delta P_{4}
$$

Since $k_{p_{1}}=k_{p_{2}}=k_{p_{2}}=k_{p_{2}}=6$, the load should be shared equally, i.e., $\Delta P_{1}=\Delta P_{2}=\Delta P_{3}=\Delta P_{4}$.

The initial set values of real power at different buses are: $P_{1}^{0}=0.5 \mathrm{pu}, P_{2}^{0}=0.5 \mathrm{pu}, P_{3}^{0}=-0.0014 \mathrm{pu}$ and $P_{4}^{0}$ $=-0.0014 \mathrm{pu}$. All these are found by load-flow analysis. Moreover, the steady-state values of real power after droop control implementation are as follows: $P_{1}=1.3734$ pu, $P_{2}=1.3734 \mathrm{pu}, P_{3}=0.872 \mathrm{pu}$ and $P_{4}=0.872 \mathrm{pu}$. Now, $\Delta P_{1}=P_{1}-P_{1}^{0}=0.8734 \mathrm{pu}, \Delta P_{2}=P_{2}-P_{2}^{0}=0.8734 \mathrm{pu}, \Delta P_{3}=P_{3}-$ $P_{3}^{0}=0.8734 \mathrm{pu}$ and $\Delta P_{4}=P_{4}-P_{4}^{0}=0.8734 \mathrm{pu}$. Therefore, $\Delta P_{1}=\Delta P_{2}=\Delta P_{3}=\Delta P_{4}$ and the proposed control scheme is robust enough to share the load equally.

\section{Effective Reactive Power Sharing}

In this section, linear model of the system is further analyzed with a view to sharing reactive power. In this case, $Y_{\mathrm{b} u s}$ matrix is not reduced and $Y_{i j}=G_{i j}+j B_{i j}$. The reactive power flow of 5-bus system becomes $(i=1,2,3,4,5)$ :

$$
Q_{i}=\sum_{j=1}^{5} V_{i} V_{j}\left(G_{i j} \sin \delta_{i j}-B_{i j} \cos \delta_{i j}\right)
$$


For negligible $G_{i j}$, it can be written $(i=1,2,3,4)$,

$$
Q_{i}=-V_{i} V_{5} B_{i 5} \cos \delta_{i 5}-V_{i}^{2} B_{55}
$$

Let there be a change in the reactive power at node- 5 due to load change and using (2) it can be written as $(i=1,2,3,4)$ :

$$
\begin{aligned}
\Delta Q_{i} & =k_{q_{i}} \Delta Q_{i} V_{5}^{0} B_{i 5} \cos \delta_{i 5}^{0}-V_{i}^{0}\left|\Delta V_{5}\right| B_{i 5} \cos \delta_{i 5}^{0} \\
& +V_{i}^{0} V_{5}^{0} B_{i 5} \sin \delta_{i 5}^{0}+2 k_{q_{i}} \Delta Q_{i} V_{i}^{0} B_{i i}
\end{aligned}
$$

The simplified form of (17) is $(i=1,2,3,4)$ :

$$
\Delta Q_{i}=\frac{-V_{i}^{0}\left|\Delta V_{5}\right| B_{i 5} \cos \delta_{i 5}^{0}+V_{i}^{0} V_{5}^{0} B_{i 5} \sin \delta_{i 5}^{0}}{1-k_{q_{i}} V_{5}^{0} B_{i 5} \cos \delta_{i 5}^{0}-2 k_{q_{i}} V_{i}^{0} B_{i i}}
$$

where, $\left|\Delta V_{5}\right|=V_{5}^{0} \sqrt{\left(\cos \delta_{5}\right)^{2}+\left(-\sin \delta_{5}\right)^{2}}=V_{5}^{0}$

Reactive power of nodes 1-4, after load change, can be found by solving (18).

\section{Simulation Results}

The power sharing performance of the proposed control strategy during load change is evaluated by means of MATLAB simulation in this section. The microgrid test system considered in this case consists of four DG units and one static load. Load impedance is varied from 1 pu to $j$ pu at 0 second in order to show the effectiveness of the controller in providing steady-state power responses.
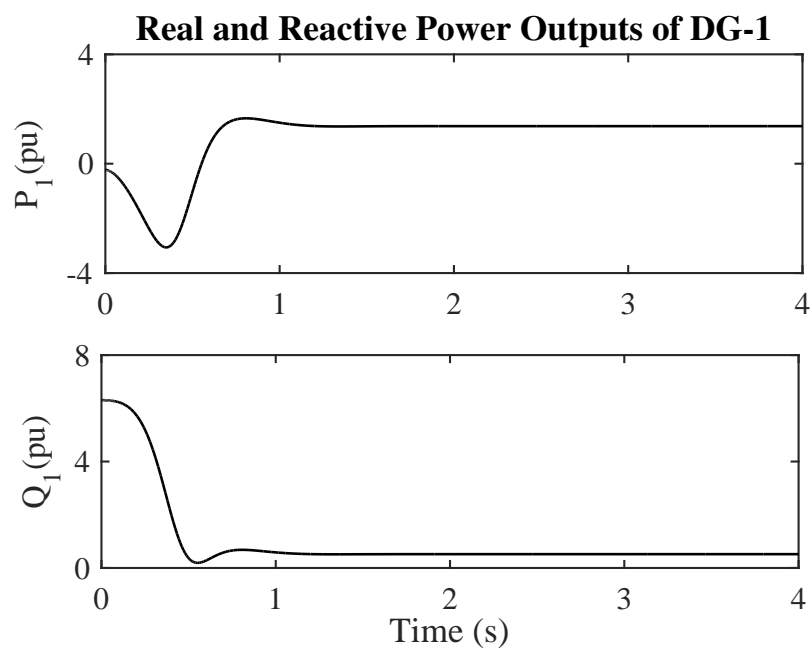

Fig. 2: Output Powers of DG unit-1

The automatic load sharing of the described scenario is demonstrated from Fig. 2 to Fig. 5. Since the controller acts in a way that DG unit-1 and DG unit-2 supply the same amount of power, the power responses of them are alike as shown in Figs. 2-3. Similar situation is also evident from other two figures (Figs. 4-5); where equal amount of power has been supplied by DG unit-3 and DG unit-4. The steady-state responses are found within 1.5 seconds in all the cases.
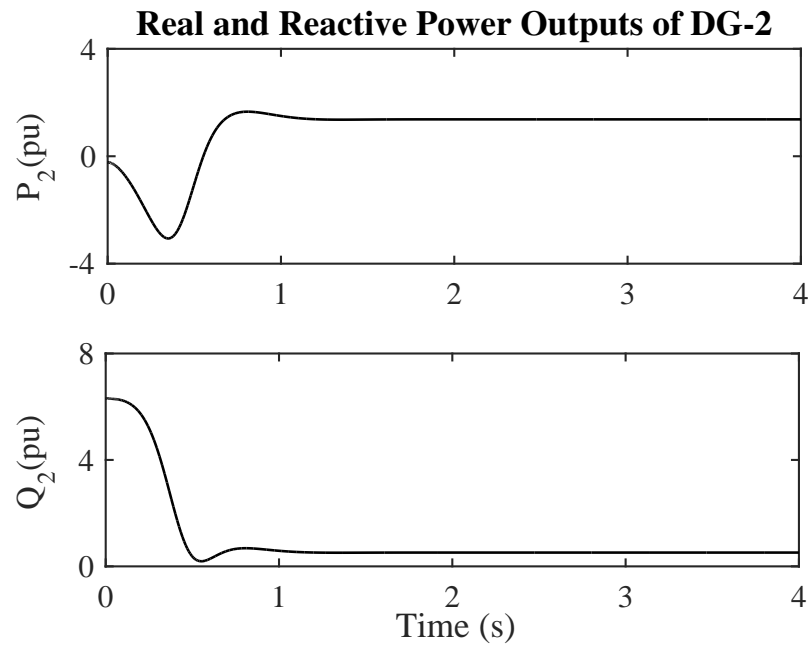

Fig. 3: Output Powers of DG unit-2
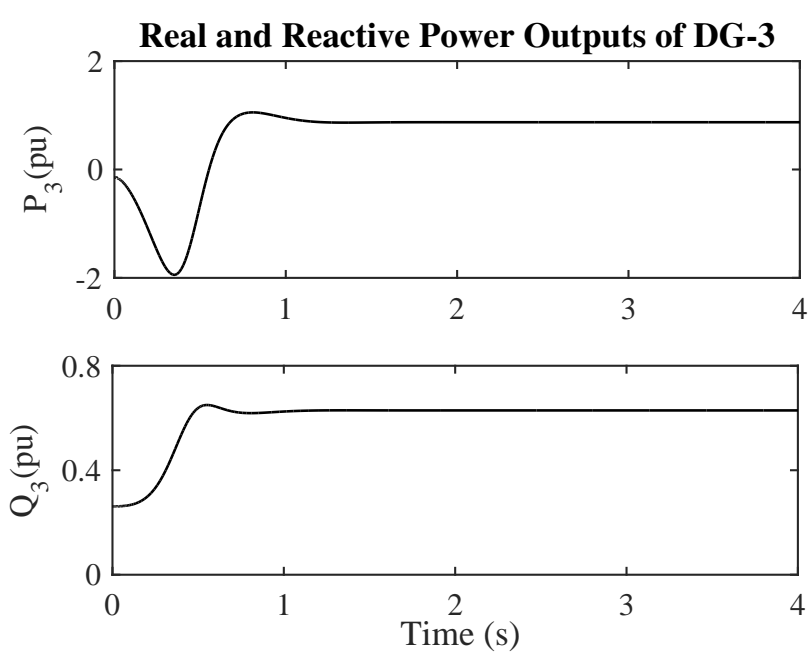

Fig. 4: Output Powers of DG unit-3
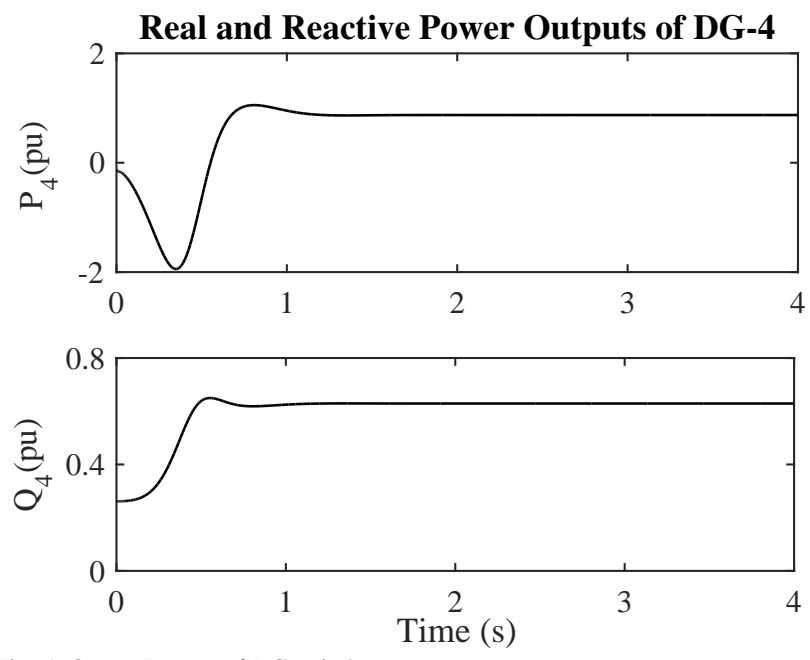

Fig. 5: Output Powers of DG unit-4

Fig. 6 indicates that load powers are also stable. This is because of the fact that load has been shared accurately. The feasibility of the proposed controller in sharing load has been 
justified by these figures.
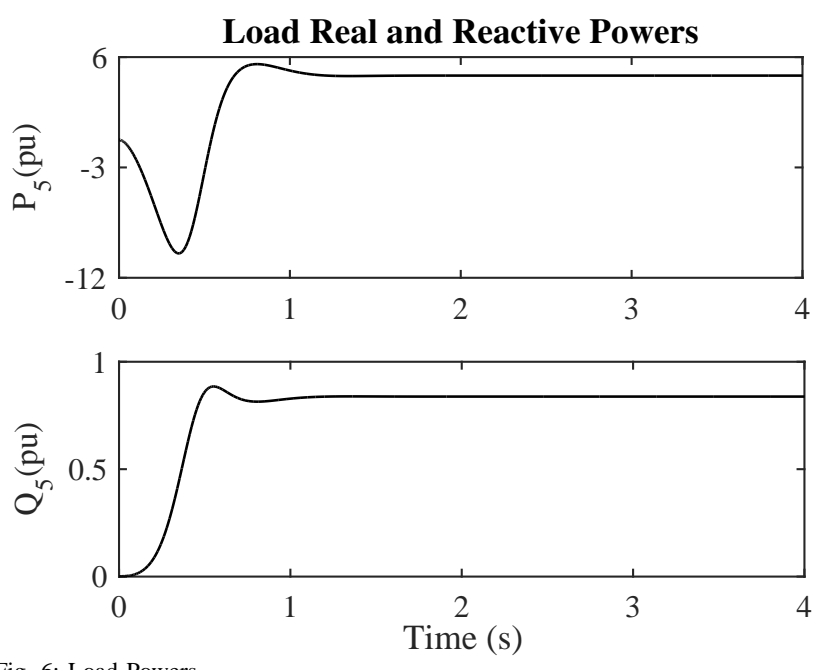

Fig. 6: Load Powers

\section{CONCLUSION}

This paper addresses an automatic droop control method to ensure stability in microgrid system, operating in an islanded mode, during load variation. The linear modal analysis and simulated results justify the viability of the proposed controller. Effective power sharing, both real and reactive, among various inverter-connected distributed generators is also outlined in this paper. The future challenge is the realistic and practical implementation of the proposed strategy in islanded microgrids.

\section{REFERENCES}

[1] M. Erol-Kantarci, B. Kantarci, and H. T. Mouftah, "Reliable overlay topology design for the smart microgrid network," IEEE Network, vol. 25 , no. 5 , pp. $38-43$, Sep.-Oct. 2011.

[2] H. Farhangi, "The path of the smart grid," IEEE Power and Energy Mag., vol. 8, pp. 18-28, 2010.

[3] R. H. Lasseter, "Smart Distribution: Coupled microgrids," in Proc. of the IEEE, vol. 99, no. 6, pp. 1074-1082, Jun. 2011.

[4] N. Hatziargyriou, H. Asano, R. Iravani, and C. Marnay, "Microgrids," IEEE Power Energy Mag., vol. 5, no. 4, pp. 78-94, Jul./Aug. 2007.

[5] M. A. Barik, H. R. Pota, and J. Ravishankar, "An automatic load sharing approach for a DFIG based wind generation in a microgrid," in Proc. IEEE Conf. on Ind. Electron. and Appl., pp. 589 - 594, Jun. 19-21, 2013.

[6] T. L. Vandoorn, B. Renders, L. Degroote, M. Meersman, and L. Vandevelde, "Power balancing in islanded microgrids by using a dcbus voltage reference," in Proc. Int. Symp. on Power Electron., Electr. Drives, Automat. and Motion, pp. 884-889, Jun. 14-16, 2010.

[7] M. J. Hossain, H. R. Pota, M. A. Mahmud, and M. Aldeen, "Robust control for power sharing in microgrids with low-inertia wind and PV generators," IEEE Trans. on Sustain. Energy, vol. PP, no. 99, pp. 1-11, May 2014.

[8] T. C. Green, and M. Prodanovic, "Control of inverter-based microgrids," Electric Power Syst. Research, vol. 77, no. 9, pp. 1204-1213, Jul. 2007.

[9] M. Prodanovic, and T. C. Green, "High-quality power generation through distributed control of a power park microgrid," IEEE Trans. Ind. Electron., vol. 53, no. 5, pp. 1107-1115, Oct. 2006.

[10] A. Tuladhar, H. Jin, T. Unger, and K. Mauch, "Control of parallel inverters in distributed ac power systems with consideration of line impedance effect," IEEE Trans. Ind. Appl., vol. 36, no. 1, pp. 131-138, Jan./Feb. 2006.
[11] J. P. Lopes, C. Moreira, and A. Madureira, "Defining control strategies for microgrids islanded operation," IEEE Trans. Power Syst., vol. 21, no. 2, pp. 916-924, May 2006.

[12] M. I. Azim, M. A. Hossain, M. J. Hossain, and H. R. Pota, "Droop control for islanded microgrids with compensating approach," in Proc. Australasian Universities Power Eng. Conf., Sep. 27-30, 2015.

[13] M. I. Azim, M. J. Hossain, and H. R. Pota, "Design of a general droop controller for islanded microgrids," in Proc. Australasian Universities Power Eng. Conf., Sep. 27-30, 2015.

[14] K. De Brabandere, B. Bolsens, J. Van den Keybus, A. Woyte, J. Driesen, and R. Belmans, "A voltage and frequency droop control method for parallel inverters," IEEE Trans. Power Electron., vol. 22, no. 4, pp. 11071115, Jul. 2007.

[15] T. L. Vandoorn, J. D. M. De Kooning, B. Meersman, J. M. Gurrero, and L. Vandevelde, "Automatic power-sharing modification of P/V droop controllers in low-voltage resistive microgrids," IEEE Trans. Power Del., vol. 27, no. 4, pp. 2318-2325, Oct. 2012.

[16] Y. Tan, K. M. Muttaqi, and L. G. Meegahapola, "A droop control based load sharing approach for management of renewable and non-renewable energy sources in a remote power system," in Proc. Australasian Universities Power Eng. Conf., pp. 1-6, Sep. 29-Oct. 3, 2013.

[17] M. I. Azim, M. J. Hossain, and H. R. Pota, "Design of a controller for active power sharing in a highly-resistive microgrid," in Proc. IfAC Symp. on Control of Power and Energy Systems, Dec. 9-11, 2015.

[18] H. R. Pota, M. J. Hossain, M. A. Mahmud, R. Gadh, and R. C. Bansal, "Islanded Operation of microgrids with inverter connected renewable energy sources," in Proc. IFAC World Congress, Aug. 24-29, 2014.

[19] H. R. Pota, "Droop control for islanded microgrids," in Proc. IEEE PES Gen. Meet., pp. 1-4, Jul. 21-25, 2013.

[20] J. W. Simpson-Porco, F. Dorfler, F. Bullo, "Voltage stabilization in microgrids via quadratic droop control," in Proc. IEEE Annual Conf. on Decision and Control, pp. 7582-7589, Dec. 10-13, 2013.

[21] H. R. Pota, M. J. Hossain, M. A. Mahmud, and R. Gadh, "Control for microgrids with inverter connected renewable energy resources," in Proc. IEEE PES Gen. Meet., pp. 1-5, Jul. 27-31, 2014.

[22] Y. Wang, H. Nazaripouya, C. Chu, R. Gadh, and H. R. Pota, "Vehicleto-grid automatic load sharing with driver preferences in microgrids," in Proc. IEEE PES Innovative Smart Grid Technologies Europe, pp. 1-6, Oct. 12-15, 2014. 